\title{
THE LARVAL STAGES OF PLEURONCODES PLANIPES STIMPSON (CRUSTACEA, DECAPODA, GALATHEIDAE)
}

CARL M. BOYD

\author{
Scripps Institution of Oceanography, ${ }^{1}$ University of California, La Jolla, California
}

The zoeal larval stages of a galatheid crab were found in large numbers (up to $42,000 / 1000 \mathrm{~m}^{3}$ ) in plankton tows taken at several stations of the Marine Life Research program of the California Cooperative Oceanic Fisheries Investigations near Magdalena Bay, Baja California, Mexico. Since these unknown larvae were found in an area where the galatheid Pleuroncodes planipes was extremely abundant, it seemed likely that they were the zoeal stages of that species.

\section{METHODS}

The larvae were tentatively identified as $P$. planipes. This identification was later confirmed by two methods: (1) the first larval stages were hatched from the eggs of the adult $P$. planipes, (2) one specimen of the fifth larval stage was caught in the process of molting to the juvenile stage, and this juvenile could be identified as $P$. planipes. Several attempts were made to follow the succession of larval molts in the laboratory. Hatching the larvae from the egg was relatively easy, and was achieved by several methods. However, no larvae survived longer than eight days, and all died before they had molted once. Plunger jars and still-water aquaria were used with variations of temperature, aeration and food (Platymonas, Chlamydomonas and Coccolithophores). The plunger jar method and a procedure described briefly by Ray (1958; p. 501), involving rotating flasks, apparently failed because of the constant vigorous tumbling of the larvae.

Adult females carrying eggs have been found in the plankton from December through March. Gravid females kept in the laboratory hatched larvae during most of that period and the same is probably true of females in nature. As larvae of all stages are found in the plankton from January to July, it has proved impossible to determine rates of development.

\section{DESCRIPTION OF THE LARVAE}

\section{Stage I (Figure 35)}

First antenna (Fig. 1). This appendage has a long, unsegmented base with two distal branches. These, the exopodite and endopodite, are continuous with the base. The former bears six setae, the latter, a long plumose spine.

Second antenna (Fig. 6). The antenna consists of a base, continuing into a long medial prickly spine, and a scale. The scale bears about eight plumose setae and is continued as an apical spine, prickly at the terminal end. On the

1 Contribution from the Scripps Institution of Oceanography, New Series. 

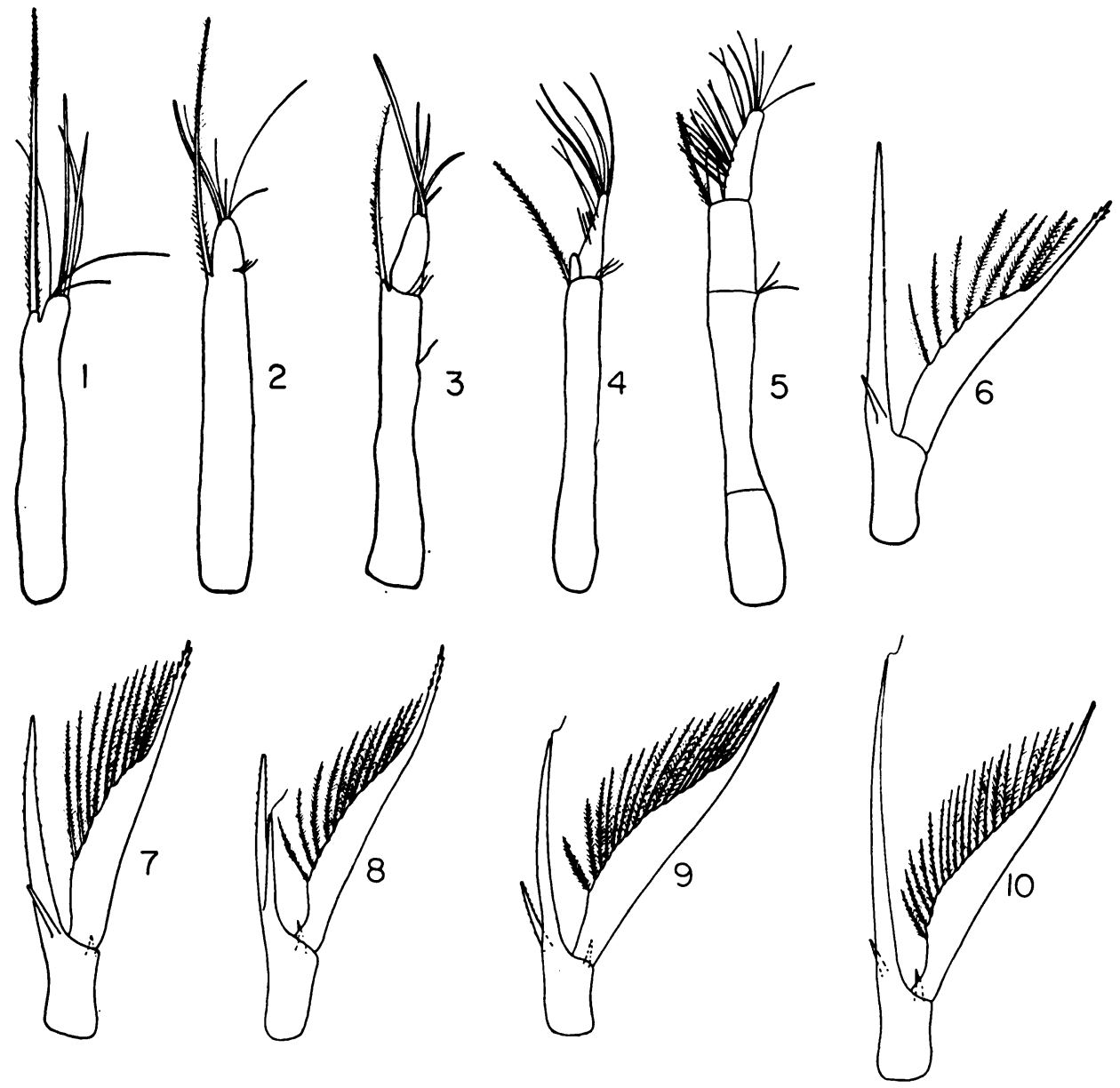

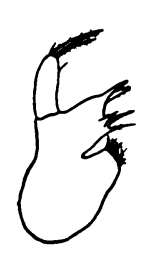

11

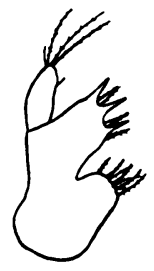

12

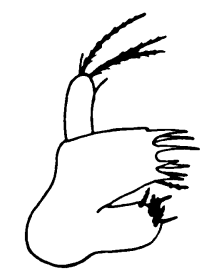

13

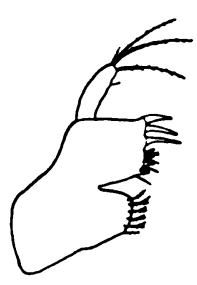

14

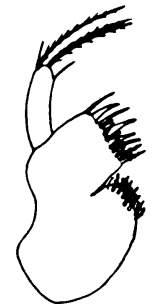

15

Figure 1. First antenna, Stage I.

Figure 2. First antenna, Stage II.

Figure 3. First antenna, Stage III.

Figure 4. First antenna, Stage IV.

Figure 5. First antenna, Stage V.

Figure 6. Second antenna, Stage I.

Figure 7. Second antenna, Stage II.

Figure 8. Second antenna, Stage III.

Figure 9. Second antenna, Stage IV.

Figure 10. Second antenna, Stage V.

Figure 11. First maxilla, Stage I.

FIgURE 12. First maxilla, Stage II.

FIGURE 13. First maxilla, Stage III.

FIGURE 14. First maxilla, Stage IV.

FIGURE 15. First maxilla, Stage V. 

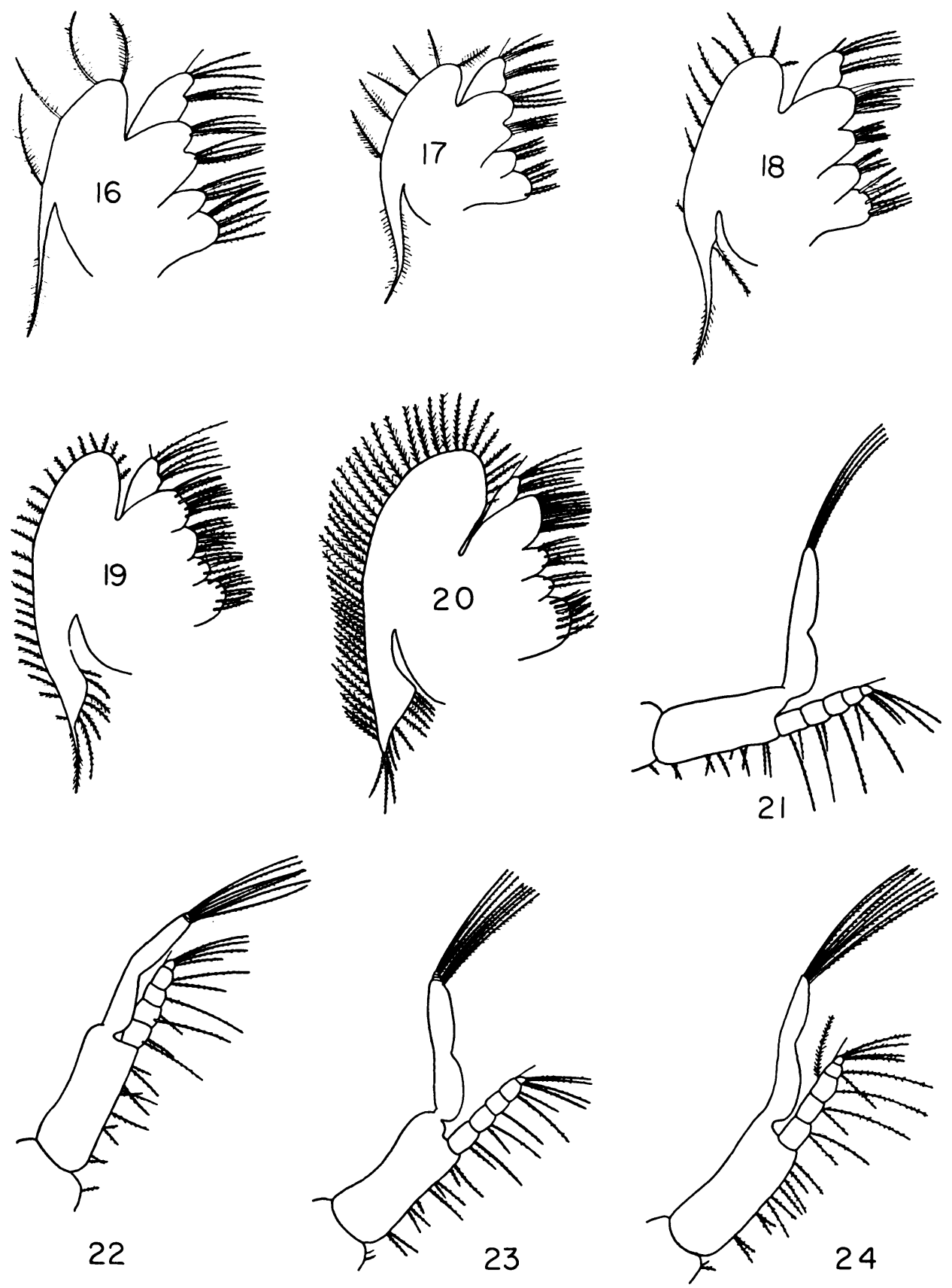

FIgURE 16. Second maxilla, Stage I.

FIGURE 17. Second maxilla, Stage II.

Figure 18. Second maxilla, Stage III.

FIgURE 19. Second maxilla, Stage IV.

FIGURE 21. First maxilliped, Stage I.

FIGURE 22. First maxilliped, Stage II.

FIGURE 23. First maxilliped, Stage III.

FIgUre 20. Second maxilla, Stage V.

FIGURE 24. First maxilliped, Stage IV and V. 
dorsal side of the inner flagellum is a smooth spine which, though small in this stage, increases in size in later stages.

Mandible. The mandible is a simple toothed process lacking a palp.

First maxilla (Fig. 11). The endopodite is a simple unjointed structure bearing three spinose setae and two smooth setae. The endopodite does not change in number of setae but only in size in the next four stages. The exopodite is split into a basipodite and a coxopodite. These generally add setae in the later stages. In Stage I, the basipodite bears five heavy setae. The coxopodite has seven setae.

Second maxilla (Fig. 16). As in the endopodite of the first maxilla, the endopodite of the second maxilla does not change the number of setae in any of the stages. Terminally on the endopodite there are four setae; three spinose and one naked. A group of three spinose setae is located subterminally. The basipodite lobes each bear four spinose setae, as does the distal lobe of the coxopodite. The proximal lobe of the latter carries six spinose setae. The scaphognathite carries only four plumose setae along its margin. Its posterior end is produced into a long plumose projection.

First maxilliped (Fig. 21). The maxilliped is well developed in the first larval stage. The appendage consists of a coxopodite with one seta on its interior margin, an unsegmented basipodite, an endopodite with five segments, and an exopodite with two indistinct segments. The basipodite has ten spinose setae on its interior margin. There are four setae terminally on the exopodite. The five segments of the endopodite each bear spinose setae, but in differing numbers. The fourth, second, and first segments have two setae, and the third but one seta. There is also one fine, smooth seta coming off from the joint of the distal (fifth) segment.

Second maxilliped (Fig. 25). The second maxilliped has much the same structure as the first. The endopodite of the second maxilliped, however, has only four segments; the third is elongated. The coxopodite has no setae; the basipodite has three spinose setae. The terminal (fourth) segment of the endopodite has four spinose setae and one fine, smooth seta. There are four setae terminally on the exopodite.

Third maxilliped (Fig. 29). The third maxilliped is rudimentary in Stage I; it lacks setae and is poorly developed in musculature. The appendage consists only of a basipodite and an exopodite; the endopodite is not present.

Abdominal segments. There are five segments, plus the telson in Stages I and II.

Telson (Fig. 36). The telson of the first larval stage has seven projections on each side. The first (outermost) is a spinose extension of the telson, and is unjointed at its base. This spine has 6-10 thorns distally. The second projection is a fine, hair-like, plumose seta. The next five are similar in that they are all plumose setae. In addition to the plumes, each seta carries thorns on its inner and outer margins.

Along the posterior margin of the telson between the plumose setae, several small thorns occur. In Stage I larvae there are usually one to three thorns between each of the inner five setae. Generally the number of thorns increases between the setae more medially located, so that there are usually two to three thorns between setae \#6 and \#7. In the medial cleft of the telson, one to three thorns 

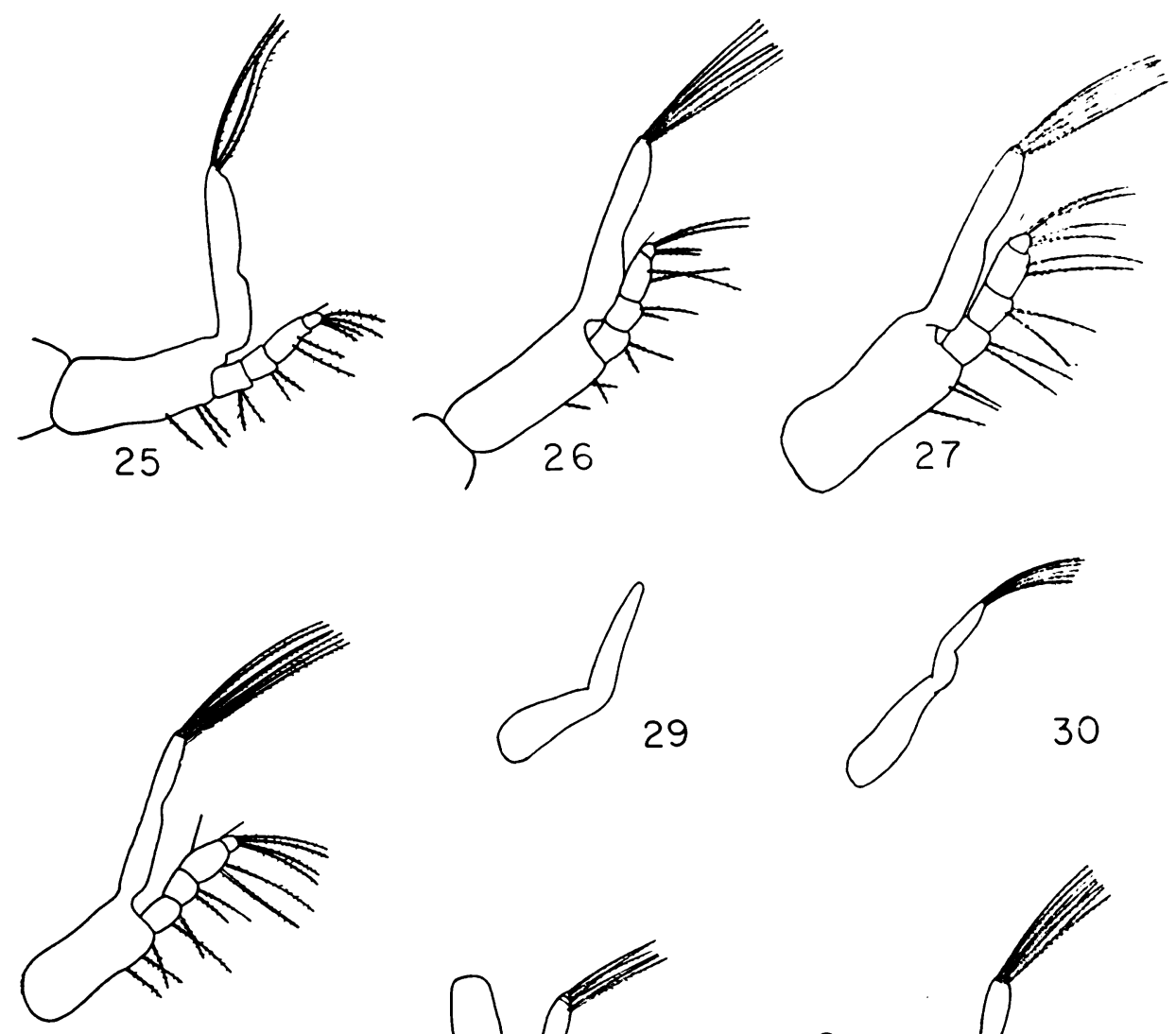

28
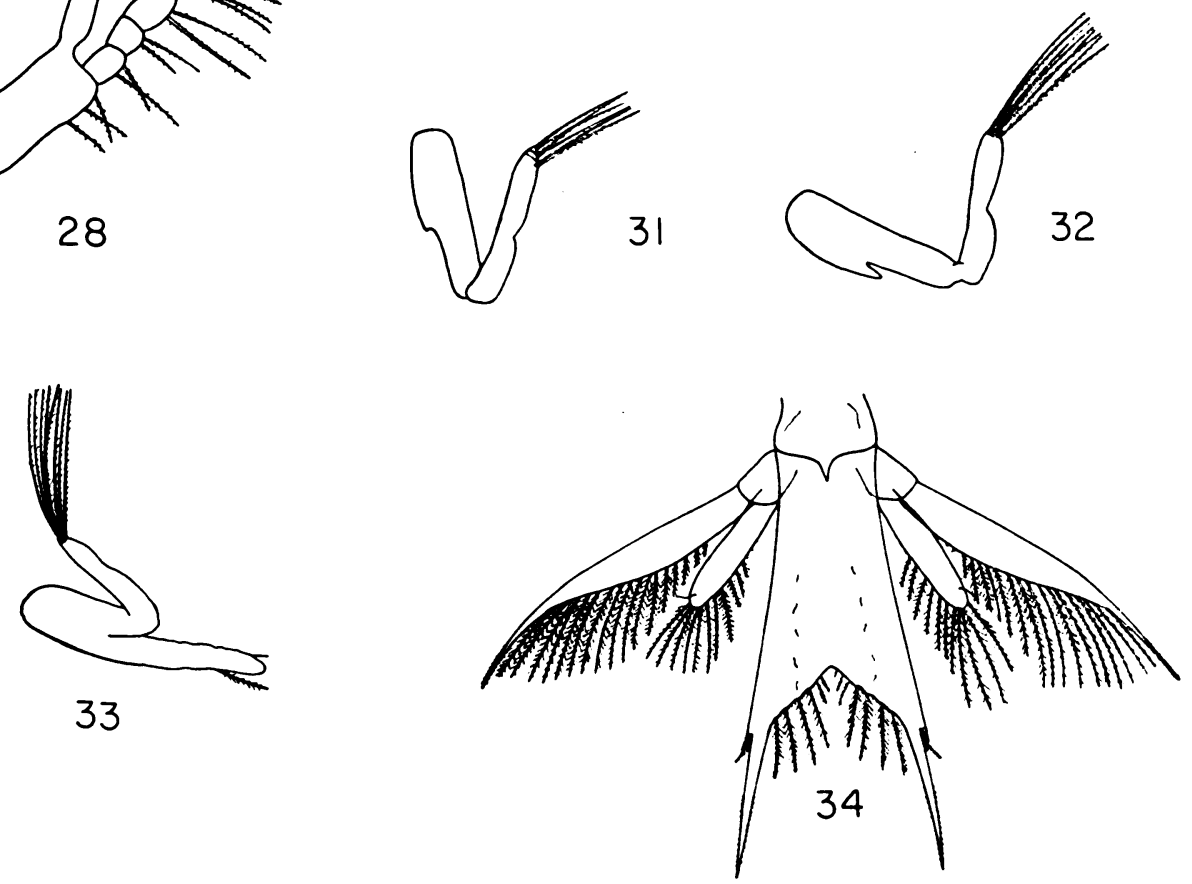

FIGURE 25. Second maxilliped, Stage I.

FIGURE 26. Second maxilliped, Stage II.

FIgURE 30. Third maxilliped, Stage II.

FIGURE 27. Second maxilliped, Stage III and IV.

Figure 28. Second maxilliped, Stage V.

FIGURE 31. Third maxilliped, Stage III.

FIGURE 32. Third maxilliped, Stage IV.

Figure 33. Third maxilliped, Stage V.

FIGURE 29. Third maxilliped, Stage I.

Figure 34. Telson, Stage IV. 
may occur on each side. A tuft of short fine hairs occurs further medially. Each tuft is composed of seven to ten hairs. The numbers of these thorns and hairs are variable and are seldom identical between the right and left halves of the telson of any individual.

\section{Stage II (Figure 37)}

First antenna (Fig. 2). This appendage is much the same as in Stage I, but here three small hairs appear toward the distal end of the base. These hairs are on the location of an ultimate segmentation appearing fully in Stage III.

Second antenna (Fig. 7). The antennal scale has gained two more plumose setae, giving it usually ten. A new spine has appeared on the ventral side of the base. This spine is not segmented from the base, but is common with it.

Mandible. No change from Stage II.

First maxilla (Fig. 12). A seta has been added to the basipodite. The coxopodite has remained unchanged.

Second maxilla (Fig. 17). The endopodite, basipodite and coxopodite are unchanged. The scaphognathite has added two marginal setae, giving a total of six.

First maxilliped (Fig. 22). There are now seven terminal setae on the exopodite.

Second maxilliped (Fig. 26). There are now seven terminal setae on the exopodite.

Third maxilliped (Fig. 30). This appears to have become a functional organ; its musculature has developed and there are six setae on the terminal end of the exopodite.

Telson (Fig. 38). The primary change in the telson of Stage II larvae is the addition of one plumose seta, increasing the number of projections to eight. In this stage, however, the third projection does not have thorns on its margins, but only plumes.

The arrangement of thorns occurring between setae is similar to that of Stage I. In Stage II, however, there are neither hairs nor thorns in the medial cleft.

\section{Stage III (Figure 39)}

First antenna (Fig. 3). The segmentation initiated in Stage II has been completed, setting the exopodite off from the base. Three hairs originate at the joint. A hair appears on the exterior lateral margin of the base. The combined length of the new terminal segment and the setae is longer than the spine of the endopodite.

Second antenna (Fig. 8). The antennal scale now usually has 11 setae. The spine on the inner flagellum has increased in length and now has a terminal hair.

Mandible. No change.

First maxilla (Fig. 13). The basipodite has eight setae, an increase of two setae over Stage II. The coxopodite is unchanged.

Second maxilla (Fig. 18). The distal lobe of the basipodite now has seven setae. The proximal lobe has six. The coxopodite is unchanged. The exterior margin of the scaphognathite now has nine setae, plus one seta located on the interior margin of the posterior end.

First maxilliped (Fig. 23). There are now eight setae on the exopodite. 


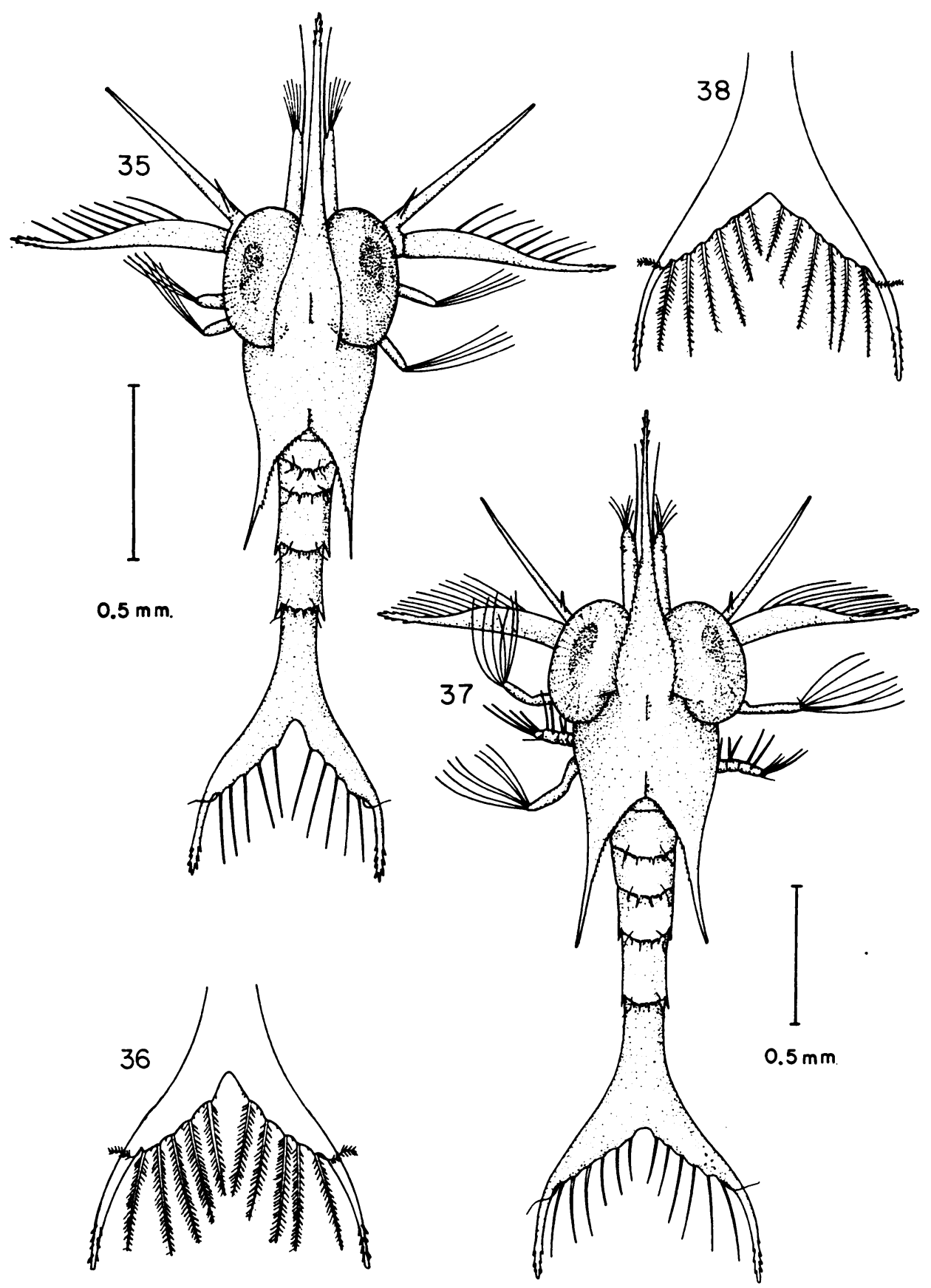

Figure 35. Larva, Stage I.

Figure 36. Telson, Stage I.

Figure 37. Larva, Stage II.

Figure 38. Telson, Stage II. 
Second maxilliped (Fig. 27). The exopodite has added one terminal seta, giving a total of eight.

Third maxilliped (Fig. 31). The only change in the third maxilliped is the development of a small bud on the basipodite.

Abdominal segments. There are six segments, plus the telson in Stages III, IV and $\mathrm{V}$.

Telson (Fig. 40). The changes in the telson between Stages II and III are radical. There are typically now nine projections on each half of the telson. The first (outermost) is a short naked spinose extension of the body of the telson. The second is a plumose hair-like seta. The third is a short heavy plumose seta. The fourth is the major projection of the telson; it is an extension of the telson and is not jointed at its base. It is covered on its interior and exterior margins by many small thorns. The fifth through the eighth projections are plumose setae bearing thorns on their lateral margins. The ninth projection is a small plumose seta lacking thorns. This innermost seta is not always present. It may be lacking on one or both sides of the telson.

Thorns are found abundantly between the fourth through the eighth projections. Between projections \#4 and \#5, zero to three thorns may occur. Usually three to five thorns are found between each of the fifth through eighth projections. Between the eighth projection and the medial line up to four hairs may be present, in addition to the ninth projection. The occurrence of these hairs is erratic.

On the dorsal surface of the telson, two pairs of very fine setae are found. The posterior pair is near the base of the seventh projection. The second pair is in line with the first pair, but anterior to it.

Uropods. The inner uropods are present only as poorly developed plates; they carry no setae. The outer uropods have from 8 to 11 plumose setae. The setae do not carry thorns. Their number is variable and may differ between the right and left sides. The tip of the outer uropod is not produced in an extended spine, but is short and naked. Small accessory setae commonly occur on the ventral surface of the outer uropod. These are not at the margin but are based somewhat anteriorly of the posterior margin. Generally there are two on each uropod, one between setae \#1 and \#2 (counting from the distal end) and the second between setae \#4 and \#5.

\section{Stage IV (Figure 41)}

First antenna (Fig. 4). The exopodite has gained three pairs of setae along its inner margin. In addition, the endopodite has developed a joint at its base.

Second antenna (Fig. 9). The scale usually now has 17 plumose setae. The spine on the inner flagellum has now increased in length so that it is much longer than the flagellum.

Mandible. The mandible at this stage has a small bud on the anterior margin which will become a palp in Stage V.

First maxilla (Fig. 14). The basipodite has 11 setae. The coxopodite has 10-11 spinose setae.

Second maxilla (Fig. 19). The lobes of the basipodite and coxopodite have added setae, but their absolute numbers are variable. The exterior margin of the scaphognathite now has about 25 setae; the posterior interior margin has six setae. 


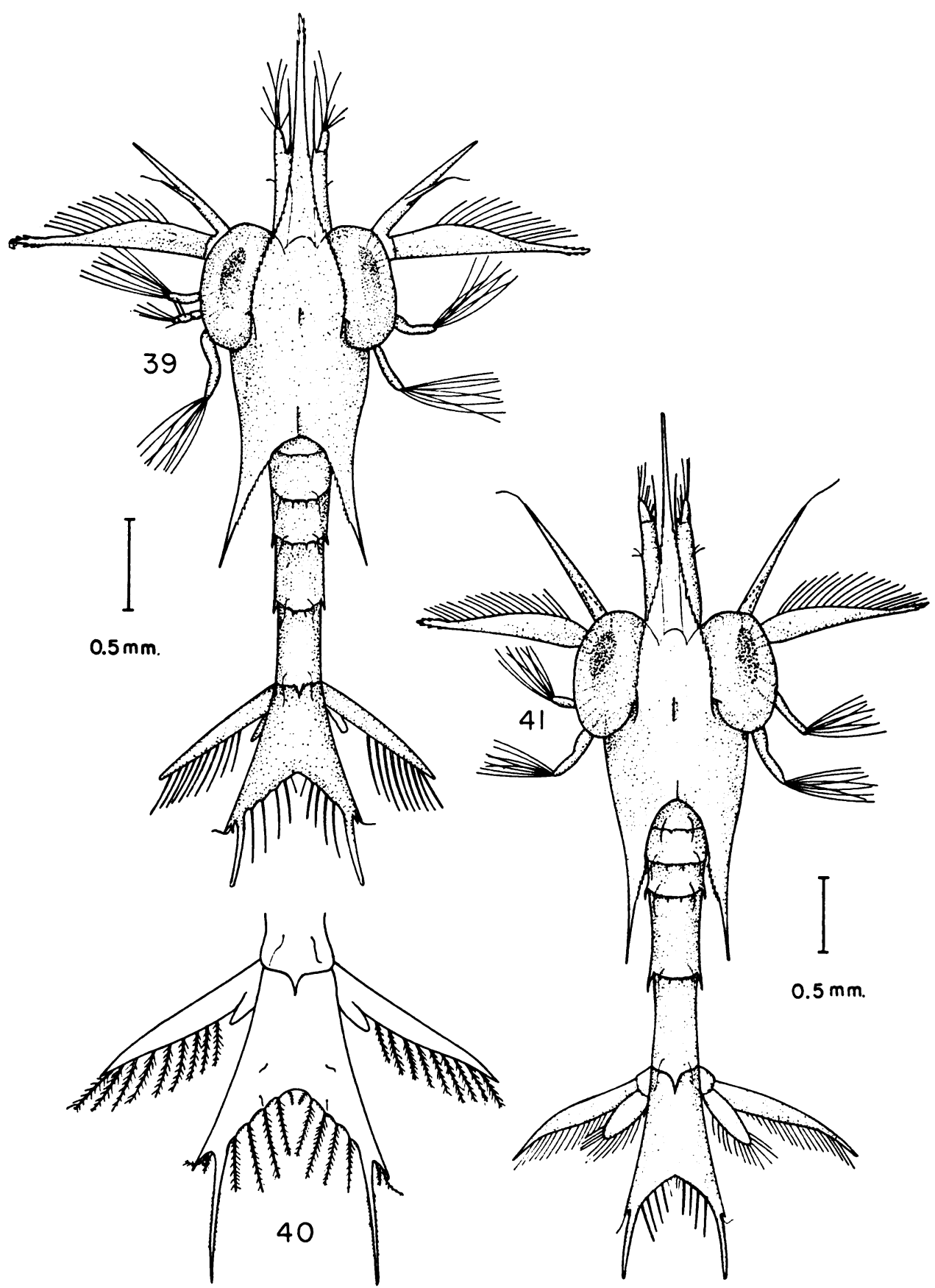

Figure 39. Larva, Stage III.

Figure 40. Telson, Stage III.

Figure 41. Larva, Stage IV. 
First maxilliped (Fig. 24). The only change from Stage II and III is in the addition of a plumose seta on the exterior margin of the third segment of the endopodite.

Second maxilliped (Fig. 27). No change from Stage III.

Third maxilliped (Fig. 32). The exopodite has added two setae, giving now a total of eight. The bud on the basipodite has somewhat increased in size from Stage III, but is still rudimentary.

Thoracic legs. Thoracic legs are not visible on Stage IV larvae from a lateral view. They are present, however, as poorly developed appendages under the carapace.

Telson (Fig. 34). The telson in this stage is similar in aspect to that in Stage III, but it has added several plumose setae. The total number of projections may vary from 10 to 12 , with the deletions occurring in the innermost setae; i.e., setae \#11 and \#12 may individually or both be absent. Typically there are 11 projections. Setae \#9, \#10, \#11, and \#12 are plumose but do not bear thorns. Projection \#1 appears to be jointed and is no longer common with the body of the telson.

On the dorsal surface of the telson there are now five pairs of fine, hair-like setae. Three pairs have been added anteriorly to those present in Stage III.

Uropods. Inner uropod: this now has from 10 to 17 plumose setae. Three tufts of hairs occur medially from the innermost seta. A fine, hair-like accessory seta is found on the dorsal surface of the distal end of the inner uropod. Outer uropod: the extremity of this branch is now extended as a long spine bearing many thorns along its lateral margins. From 13 to 21 plumose setae are present on the posterior margin of this branch. Several fine hairs are found medially of the innermost seta. Four accessory setae are again found on the ventral surface of the outer uropod. These commonly occur between setae \#1 and \#2, \#4 and \# , \#9 and \#10, and \#14 and \#15, starting from the outer seta.

\section{Stage V (Figures 42-44)}

First antenna (Fig. 5). The exopodite has added more medial setae, bringing the total to about 22. The endopodite has elongated, but is still shorter than the exopodite. The base now appears to be very lightly segmented into three parts.

Second antenna (Fig. 10). The number of plumose setae on the scale has increased to usually 19 . The inner flagellum is reduced to a very small size and the spine which formerly grew upon it is as long as the antennal scale.

Mandible. The palp on the anterior margin is well developed, though unsegmented.

First maxilla (Fig. 15). The basipodite has about 15 setae and the coxopodite has about 13 setae.

Second maxilla (Fig. 20). The basipodite and coxopodite have added setae. The scaphognathite now has about 43 plumose setae on its exterior margin. Its posterior interior margin now has eight setae. The extreme posterior spine has been replaced by three plumose setae.

First maxilliped (Fig. 24). Unchanged from Stage IV.

Second maxilliped (Fig. 28). The only change from Stage III and IV is in the addition of a smooth seta on the exterior margin of the third segment of the endopodite. 
Third maxilliped (Fig. 33). At this stage the endopodite appears. However, it is soft, poorly musculatured and unsegmented. On its interior margin is a plumose seta and on its exterior margin, distally, is a fine smooth seta.

Thoracic legs. The thoracic legs are easily visible in a lateral view of the Stage V larvae. The first is chelate, the fifth is quite small and hidden behind the fourth leg.

Pleopods. There are now four pairs of unequally bifid pleopods present.

Telson (Fig. 43). The telson of this stage has reached its full development and variability of spine count is reduced. There are now commonly 12 projections. Of the inner eight projections, only \#5 through \#8 have thorns as well as plumes on their margins. One to five thorns are found on the margins of the telson between each of projections \#4 through \#9. No thorns are found medially of the ninth projection, but up to three hairs may occur between each of the setae between the ninth projection and the medial line. The five pairs of fine dorsal accessory setae of Stage IV are unchanged in Stage V.

Uropods. Inner branch: the inner branch now has from 18 to 21 plumose setae. Several hairs are found medially of the innermost setae. The fine setae occurring on the dorsal surface of the distal tip of the inner uropod in Stage IV is still found in this stage. Outer branch: the characteristic form of the outer uropod has not changed from that of Stage IV. The tip of the uropod is still drawn out as a spine and still bears thorns on its lateral margins. In this stage there are from 20 to 23 plumose setae on the posterior margins of the outer uropods. Fine, accessory setae occur ventrally between \#1 and \#2, \#4 and \#5, \#9 and $\# 10$, and \#14 and \#15.

\section{The Larval Stages}

The five larval stages may be separated by the following key:

\section{A. Uropods absent}

1. The posterior margin of the telson has five plumose setae on each side; the third maxilliped is rudimentary.

ST AGE I

2. The telson has six plumose setae on each side; the third maxilliped is functional.

STAGE II

B. Uropods present

1. The inner uropods are naked; pleopods are absent.

ST AGE III

2. The inner uropods have setae; pleopods are absent.

3. Pleopods are present.

The sizes (total lengths) of the larvae in each stage were as follows (range and mean):

$\begin{array}{llllc}\text { Stage } & \text { Minimum } & \text { Mean } & \text { Maximum } & \begin{array}{c}\text { Number } \\ \text { measured }\end{array} \\ \text { I } & 2.6 \mathrm{~mm} . & 2.7 \mathrm{~mm} . & 2.8 \mathrm{~mm} . & 8 \\ \text { II } & 3.1 & 3.4 & 3.6 & 8 \\ \text { III } & 4.1 & 4.6 & 5.0 & 7 \\ \text { IV } & 5.3 & 5.7 & 6.5 & 11 \\ \text { V } & 7.2 & 7.6 & 7.8 & 11\end{array}$

All the larvae measured and figured were from the Magdalena Bay area. 


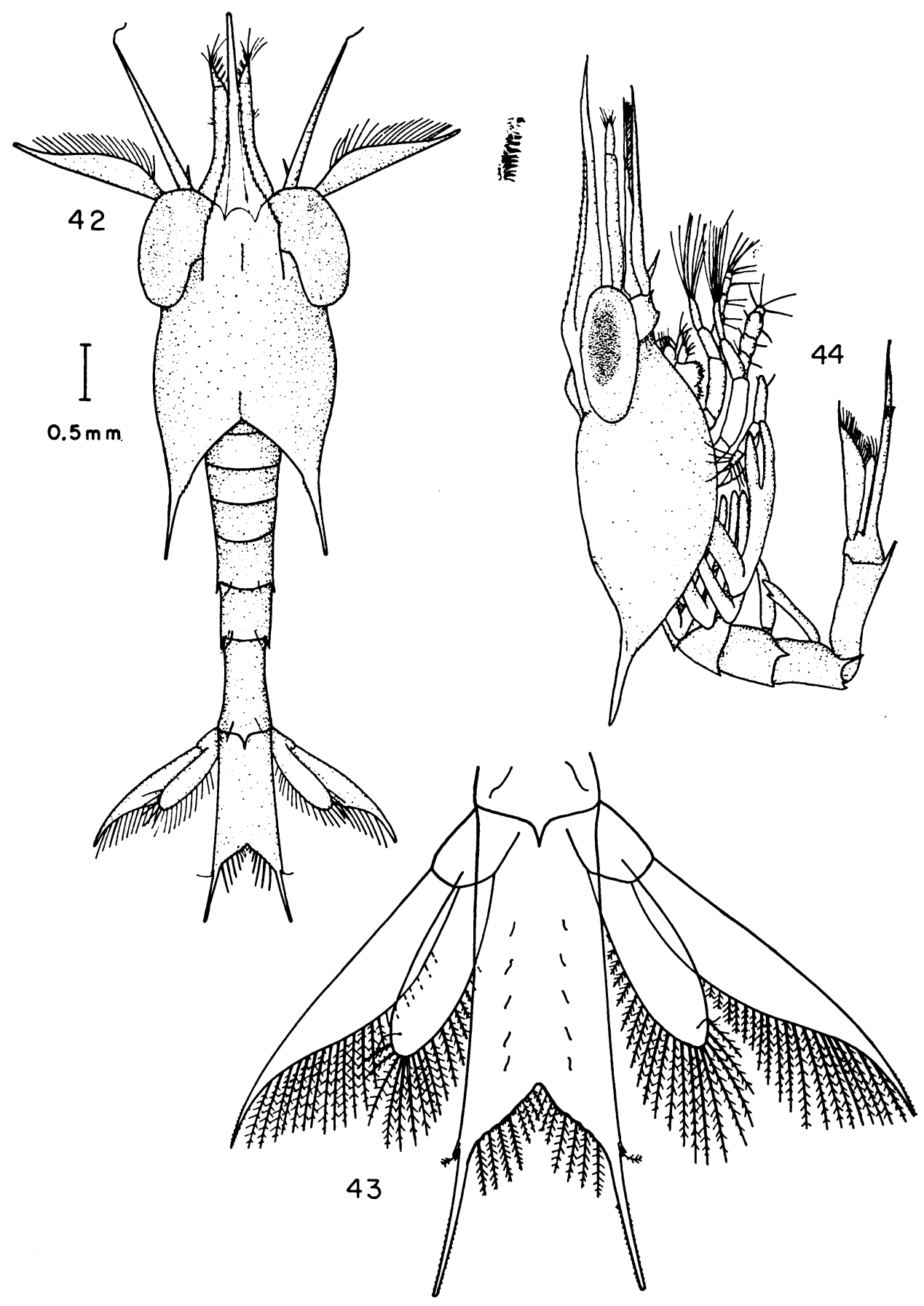

Figure 42. Larva, Stage V.

Figure 43. Telson, Stage V.

Figure 44. Larva, Stage V. 
Lebour (1930) notes that Galathea dispersa may omit either Stage IV or V, but that there are usually five stages. It is not known if all $P$. planipes larvae pass through each of the five stages before molting to the juvenile stage; one or more stages may be by-passed. However, the measurements given above indicate that this is infrequent.

\section{Discussion}

All except one of the developmental features of Munida and Galathea larvae as described by Lebour $(1930 ;$ p. 177$)$ are also found in $P$. planipes: the pleopods do not appear as small knobs in the third stage in $P$. planipes, but appear without previous indication in the fifth stage. Pleuroncodes larvae share the following traits with larvae of Munida, but not with those of Galathea: the endopod of the first maxilla has only one segment; in Stages I and II the lateral-most spine of the telson of both Munida and Pleuroncodes is longer than any of the posterior margin on the telson; a large dorsal spine occurs on the posterior margin of the sixth abdominal segment in Stages III, IV and V. Pleuroncodes thus appears to be more closely related to Munida than to Galathea.

The larval stages of five species of the genus Munida have been described. G. O. Sars described the larvae of $M$. sarsi Brinkman in 1889. Johan Huus (1934) found that these were morphologically identical with the larvae of $M$. tenuimana M. Sars, with the exception of some minute hairs in the medial cleft of the telson. Lebour (1930) described the larval stages of $M$. rugosa (Fabricius) and later (1931) set up a key to distinguish the galatheid larvae of the Plymouth area. $M$. rugosa is, however, the only species of the genus Munida covered by this key. (Lebour described the larvae as $M$. banffica; Zariquiey (1952), however, has synonymized this species with $M$. rugosa.) Rayner (1935) described five larval stages of $M$. gregaria (Fabricius) and $M$. subrugosa (White) but was unable to distinguish the larvae of the two species. The adults of these two species are limited to the southern hemisphere and along the Eastern Pacific they do not occur north of $41^{\circ} 30^{\prime}$ S. (Matthews, 1932; p. 470).

Larvae of Pleuroncodes planipes can be easily distinguished from the described larvae of European munids by the aciculate second antennae and the elongated postero-lateral spines of the carapace of the latter. They are, however, very much like the larvae of the New World munids described by Rayner (1935). The chief difference is the lack of serration on the lateral margins of the rostrum of the larvae of $M$. gregaria and $M$. subrugosa. The rostrum of each of the stages of $P$. planipes, except the first, is strongly serrated. The fifth stage of the Munida species has some serration on its rostrum, but not to the degree found in $P$. planipes. Rostral serration probably will not hold good in the future as a valid characteristic setting off the genus Pleuroncodes, for Gurney $(1942$; p. 255) mentions an unidentified galatheid larva from Bermuda which had a serrated rostrum. No species of Pleuroncodes is known from that area.

Both Huus (1934) and Lebour $(1930,1931)$ use color and arrangement of pigmented areas as an aid to specific identification. All color fades, however, from specimens kept longer than a few weeks in either alcohol or formalin. No color pattern was noted in $P$. planipes for that reason.

The area off Magdalena Bay $\left(24^{\circ} 40^{\prime} \mathrm{N} ., 112^{\circ}\right.$ W.) appears to be peculiar as far as $P$. planipes larvae are concerned. Within a 50 -mile radius of this bay, 
densities up to $42,000 / 1000 \mathrm{~m}^{3}$ have been observed and are not uncommon. Outside this area, but well within the usual distributional area of adult $P$. planipes, the larvae, as sampled with a meter net from $140 \mathrm{~m}$. to the surface, have an average density of $5 / 1000 \mathrm{~m}^{3}$ (based on 22 tows taken between January and July; range $0-26 / 1000 \mathrm{~m}^{3}$ ). On this evidence it would appear that the Magdalena Bay area is a center of breeding. This is somewhat unusual in that adults are considered epi-pelagic and are distributed over a very wide range, from about $16^{\circ} \mathrm{N}$. to $36^{\circ} \mathrm{N}$. and from the littoral to several hundred miles off-shore.

The author wants to express his thanks to Dr. Martin W. Johnson for the help he has given me in this study. The author is also grateful for the assistance of Dr. E. W. Fager and Mrs. Margaret K. Riedel in criticism and preparation of this paper.

\section{SUMMARY}

The larval stages of a galatheid decapod crustacean, Pleuroncodes planipes, have been identified, described and figured. There are five stages. First stage larvae were hatched from eggs carried by adults; no larvae molted under laboratory conditions. Larval morphology indicates that the genus Pleuroncodes is more closely allied to the genus Munida than to Galathea. The larvae occur in high densities $\left(42,000 / 1000 \mathrm{~m}^{8}\right)$ in the region of Magdalena Bay, Baja California, Mexico.

\section{LITERATURE CITED}

GuRney, Robert, 1942. Larvae of Decapod Crustacea. 306 pp. The Ray Society, London.

HuUs, Joн AN, 1934. Zur morphologisch-systematischen und biologischen Kenntnis der nordischen Munida-Larven (Crustacea Decapoda). Bergens Museums Arsbok, Naturvidenskapelig rekke, 1934 : 1-32.

Lebour, Marie V., 1930. The larvae of the Plymouth Galatheidae. I. Munida banffica, Galathea strigosa and Galathea dispersa. J. Mar. Biol. Assoc., 17 : 175-188.

Lebour, Marie V., 1931. The larvae of the Plymouth Galatheidae. II. Galathea squamifera and Galathea intermedia. J. Mar. Biol. Assoc., $17: 385-390$.

Matthews, L. Harrison, 1932. Lobster-krill; anomuran crustacea that are the food of whales. Discovery Reports, 5 : 467-484.

RAy, D. L., 1958. Some marine invertebrates useful for genetic research. In: Perspectives in Marine Biology, edited by A. A. Buzzati-Traverso, pp. 497-512.

Rayner, G. W., 1935. The Falkland species of the crustacean genus Munida. Discovery Reports, 10: 209-245.

SARS, G. O., 1889. Bidrag til Kundskaben om Decapodernes Forvandlinger II. LithodesEupagurus, Spiropagurus-Galathodes-Galathea-Munida-Porcellana-(Nephrops). Archiv. for Mathematik og Naturvidenskab, 13, 1889-1890: 132-201.

Zariquiey Alvarez, Ricardo, 1952. Estudio de los especies Europea, del Gen. Munida Leach 1818. Eos; Revista Espanola de Entomologia, 28: 143-231. 